\title{
A educação básica na proposta da Confederação Nacional da Indústria nos anos 2000
}

Alessandro de Melo

Universidade Estadual do Centro-Oeste

\section{Resumo}

0 presente artigo, fruto de uma tese de doutorado, tem como propósito apresentar e discutir criticamente a proposta de educação básica da Confederação Nacional da Indústria (CNI), por meio da descrição e da análise de alguns documentos da entidade expostos publicamente ao longo dos anos 2000. 0 projeto de educação básica dos empresários brasileiros contempla a necessidade dessa classe de competir no mercado globalizado e em crise, vinculando o aumento do nível de escolaridade ao aumento da produtividade e da inovação necessárias para sua consecução. As bases de tal projeto educativo são a retomada da teoria do capital humano, a empregabilidade e o empreendedorismo. Em termos de projeto social, os empresários remetem-se a um pacto social, ou seja, pretendem generalizar uma concepção de mundo em que não caberia o conflito entre capital e trabalho, mas sim a adaptação dos trabalhadores à sociedade de classes. Nessa concepção, a ênfase recai sobre um projeto educativo que visa à responsabilização dos indivíduos por suas próprias carreiras; assim, a inserção ou exclusão social não é vista como resultante da estrutura macrossocial, mas do esforço individual empreendido, ou seja, da capacidade de o trabalhador ser organicamente produtivo para o capital.

\section{Palavras-chave}

Educação básica - Confederação Nacional da Indústria Empreendedorismo - Capital humano - Empresariado e educação. 


\title{
Basic education as proposed by the National Confederation of Industry in the 2000s
}

\author{
Alessandro de Melo
}

Midwest State University

\begin{abstract}
This article has resulted from a doctoral thesis and it aims first to present and then to critically analyze the proposal of basic education of the National Confederation of Industry - CNI, by describing and analyzing some documents of the confederation, publicly exposed over the 2000s. The basic education project of the Brazilian business community attempts to meet need of this class to compete in the globalized and in crisis market, linking the increase in the level of education with the increase in productivity and innovation needed to achieve this project. The basis of this educational project is the return to the human capital theory, employability and entrepreneurship. In terms of social project, the businessmen refer to a social pact, that is, they intend to generalize a worldview to which applies not the conflict between capital and labor but the adaptation of workers to the class society. In such conception the emphasis is on an educational project that seeks accountability of individuals for their career. Therefore, their inclusion or exclusion should be considered not a result of the macro-social structure, but a result of the individual effort to succeed, i.e., the worker's ability or lack of ability to be organically productive for the capital.
\end{abstract}

\section{Keywords}

Basic education - National Confederation of Industry Entrepreneurship - Human capital - Business community and education. 


\section{Introdução ou um necessário roteiro teórico para a leitura dos documentos da CNI}

Os empresários brasileiros reunidos na Confederação Nacional da Indústria (CNI), a mais importante entidade agremiadora da burguesia nacional, vêm apresentando - ao longo da história da entidade, que se inicia no final da década de 1930 - propostas educacionais para o país, investindo sobre os governos para que essas propostas transformem-se em políticas públicas de Estado. Tais propostas, sem prejuízo das diferenças históricas, sempre se vincularam à formação do trabalhador qualificado para a indústria, em conformidade com as transformações produtivas e com vistas à manutenção e melhoria das possibilidades de competitividade do país. No projeto empresarial, portanto, educação, inovação, produtividade e competitividade são fatores sine qua non para o desenvolvimento nacional.

0 que é preciso compreender para a leitura dos documentos mais recentes da CNI é o cenário capitalista vigente desde os fins do século XX e na atualidade. Tal cenário é caracterizado pela ampla e radical competitividade da indústria brasileira com as indústrias do mundo inteiro. Quanto mais extensa e radical é essa competição, mais necessário se faz tornar melhores os fatores que ampliam a competição da indústria nacional; dentre esses fatores, a educação não é de menor importância, e sempre está presente nos documentos da entidade.

A questão levantada de um ponto de vista crítico é a redução da educação à formação de capital humano, o que é um projeto unidimensional de formação para o trabalho abstrato, e não um projeto emancipatório de educação.

Outra questão que este artigo pretende apenas levantar para futuras discussões é a universalização desse projeto educativo da CNI, representante da classe dominante mais avançada do país, como um projeto nacional, consenso este alcançado, entre outros meios, pela ênfase na qualidade da educação básica, objetivo praticamente indiscutivel desde a década de 1990 e que, no seio do projeto empresarial, ganha contornos específicos que precisam ser esclarecidos.

Como não é possível aprofundar essa discussão aqui ${ }^{1}$, é relevante apenas contextualizar que a produção capitalista sobre bases microeletrônicas tem refletido em demandas por trabalhadores que possuam uma base de qualidade da educação básica em relação às competências matemáticas, de ciências e de leitura e escrita.

Outro fator de destaque na leitura dos documentos da CNI é a constante retomada da teoria do capital humano, revitalizada, no referido período histórico, com discursos (mas não com práticas ${ }^{2}$ ) acerca do fim dos paradigmas tayloristas/fordistas, quais sejam: a rígida hierarquização das funções fabris e um tipo de trabalho repetitivo que não exige qualificação. Tudo isso leva, segundo a CNI, a que o discurso da luta entre capital e trabalho torne-se obsoleto e contraproducente frente aos desafios do desenvolvimento do pais ${ }^{3}$.

Com relação à teoria do capital humano, esta é derivada das clássicas teses de Theodore Schultz (1973) e, no Brasil, de Mário Henrique Simonsen (1975), e relaciona investimentos em educação à sua efetividade no que se refere a seus resultados produtivos. A CNI constata que, embora os investimentos no Brasil não estejam fora das margens de outros países em melhores condições que as nossas, seus resultados são pífios, o que se expressa na má qualidade de nossa educação apontada nos testes internacionais, legitimados em todos os documentos da entidade. A relação entre escolaridade e renda, já apontada no Brasil por Simonsen (1975), é um dos fatores mais

1- Recorremos a Melo $(2009,2010 a)$ e aos estudos de Kuenzer (2000, 2003, 2004, 2007), de Frigotto (2007), de Ferretti (2002, 2003), de Oliveira (1996), de Invernizzi (2000) e de Salm e Fogaça (1993). Os empresários focam suas propostas no nível fundamental da educação básica.

2- Cf. Melo (2010b).

3 - Remetemos às discussões de Boito Júnior $(2003,2005,2007)$ sobre a aproximação do governo Lula com os empresários. 0 PDE (Decreto n ${ }^{\circ}$ 6.094, de 24 de abril de 2007) é um exemplo do consenso estabelecido entre capital, trabalhadores e governo acerca da educação. 
determinantes da adesão dos trabalhadores a esse pensamento, o que é socialmente visível no investimento que as famílias fazem na educação das novas gerações ${ }^{4}$.

Crítico dessa concepção, Gaudêncio Frigotto (1984) afirma que a retomada da teoria do capital humano na década de 1990 dá-se justamente num momento de refluxo das relações entre capital e trabalho, ou seja, em um momento de precarização do trabalho, o que a CNI define como necessidade de flexibilizar as contratações e demissões, num período em que

se rearticula a dominação imperialista, a competição intercapitalista impele a uma incorporação crescente do progresso técnico ao processo de produção, cindindo de forma cada vez mais radical o processo de trabalho; se delineia, de forma cada vez mais acentuada, a divisão internacional da força de trabalho; o processo de automação, em suma, só tende a rotinizar, simplificar e desqualificar o trabalho, mas também, sob as relações capitalistas tende a aumentar o subemprego e o desemprego e exasperar a extração de mais-valia. (p. 219)

Portanto, ao analisar os documentos dos empresários brasileiros, não podemos deixar de levar em conta um fator fundamental, que é o fato de que a extração da mais-valia tornase cada vez mais acirrada conforme se amplia a concorrência e reduzem-se as margens de lucro, exigindo a ampliação, em nível mundial, do mercado consumidor das mercadorias produzidas, estratégia que a China tem utilizado tão bem como quase nenhum outro país.

Outra categoria que emerge da leitura e que precisa ser esclarecida é o empreendedorismo. Tal categoria, como demonstrou Melo (2010a), é central num projeto de sociabilidade regido pelo individualismo e pela responsabilização individual. Trata-se de um discurso

4 - Sobre este tema, é interessante a leitura dos estudos derivados da sociologia da educação de Pierre Bourdieu: Bourdieu (2007a, 2007b), Nogueira (2002), Nogueira e Aguiar (2007), Costa (2010). adequado à falta de perspectivas de emprego formal e de qualidade para toda a população, ao mesmo tempo em que aparece como politicamente correto ao imprimir positividade à capacidade criadora do brasileiro, senso comum muito difundido acerca de nossa personalidade. Ser empreendedor, portanto, é colocar a criatividade na frente do projeto pessoal e ter competência técnica para realizar tal projeto, em conformidade com as oportunidades que existem ou podem aparecer. De toda sorte, o empreendedorismo passa a justificar individualmente o fracasso do modelo capitalista, cada vez mais pautado pela exclusão social e pela destruição dos recursos naturais em nome da voracidade autodestrutiva da acumulação.

Outro fator que torna a educação um implemento fundamental é sua relação com a inovação. A inovação é também uma contingência dos capitalistas em busca de sua perpetuação no mercado. Com o acirramento da concorrência, somente quem consegue alcançar vantagens competitivas mantémse de forma sustentável, produzindo e ampliando a acumulação, condição inelutável do capitalista. Isso já era constatado por Karl Marx e Friedrich Engels no Manifesto comunista de 1848, ou seja, o capitalista precisa sempre revolucionar os meios de produção e ampliar cada vez mais o mercado consumidor, transformando-se em classe mundial, o que de fato ocorre atualmente.

Por meio da inovação, os capitalistas conseguem obter vantagens competitivas ao colocar no mercado um produto com diferencial ainda não atingido pelos demais; dito de outro modo, ao inovar, a indústria fica, por determinado tempo, sem concorrentes no segmento inovado. Mas esse período de tempo é cada vez menor, pois a disseminação das tecnologias torna as inovações de fácil acesso a todos os capitalistas. No entanto, o Estado brasileiro não tem auxiliado nesse processo, uma vez que não incentiva a inovação ou cria barreiras burocráticas e de custos. Por se tratar de uma atividade de risco, os empresários 
demandam apoio governamental na parceria ou na compra de produtos inovados, de modo a incentivar as empresas.

A partir desses princípios, o artigo será dividido em quatro partes, correspondentes a quatro documentos analisados, os quais são as principais publicações da CNI a partir de 2005. Na primeira parte, será estudado o Mapa estratégico da indústria 2007-2015 (CNI, 2005), síntese do projeto nacional da entidade para o próximo período. Na segunda parte, será analisado o mais importante documento educacional da CNI nos anos 2000, denominado Educação para a nova indústria (CNI, 2007). Na terceira, será abordado o documento que a CNI produziu para o diálogo com os candidatos à Presidência da República, em 2010, denominado A indústria e o Brasil: uma agenda para crescer mais e melhor (CNI, 2010a). Na última parte, será analisado o documento mais recente da CNI, Competitividade Brasil 2010: uma comparação com países selecionados (CNI, 2010b), em que a entidade foca esforços em descortinar as necessidades do país para se tornar mais competitivo, partindo da constatação de sua baixa colocação em relação a outros países equivalentes no mundo

\section{- Mapa estratégico da indústria 2007-2015}

0 Mapa estratégico da indústria 2007-2015 (CNI, 2005) é o mais importante documento da CNI nos anos 2000 e expressa a ação articulada do Sistema Indústria e do Fórum Nacional da Indústria $\left(\mathrm{FNI}^{5}\right)$ no período, visando a um cenário mais competitivo em 2015.

A educação é apresentada nesse documento como um pilar das propostas empresariais para o futuro do país, devido à ênfase do projeto na necessidade de inovação e agregação

5 - Segundo consta no site da CNI (<http://www.cni.org.br>), o FNl, criado em 2003, consiste em "um órgão colegiado de natureza consultiva da Diretoria da CNI, atuante na formulação de estratégias sobre matérias de interesse da indústria e da economia brasileira". de valor dos produtos como fatores de competitividade da indústria. Para que tal cenário se realize, segundo o documento,

É imprescindivel prover um ambiente de geração e disseminação de conhecimentos em grande escala, fundado no acesso amplo às tecnologias de informação, no desenvolvimento de competências profissionais e humanas adequadas às necessidades do setor produtivo e no fomento ao empreendedorismo e à criatividade. (p. 31)

A educação encontra-se no projeto empresarial como elemento propulsor de acesso à informação, competência que exige formação básica de qualidade e domínio dos elementos lógicos de leitura, escrita e cálculo. Tais competências embasam a aquisição das Tecnologias da Informação (TI), bem como o desenvolvimento das competências laborativas e humanas adequadas ao cenário produtivo flexível, de base microeletrônica.

Os empresários pleiteiam a qualidade e a universalização da educação básica, elementos fundamentais para a formação dos trabalhadores, haja vista a baixa qualificação destes na indústria brasileira. Nesse sentido, os empresários afirmam como principais desafios para a educação básica a necessidade de melhorar a qualidade do ensino fundamental e de ampliar as vagas para o ensino médio (CNI, 2005).

Sinteticamente, o projeto para a educação básica dos empresários é assim apresentado:

Em um ambiente marcado pela crescente competição e por contínuas mudanças tecnológicas, a educação básica de qualidade assume um papel fundamental para o desenvolvimento das empresas e de uma economia competitiva. Para alcançar esse objetivo, é preciso implantar a gestão de qualidade nas escolas e melhorar a formação e remuneração do professor. Manter os alunos na escola por todo o período da 
educação básica é um importante desafio. A indústria conta com um contingente de trabalhadores com escolaridade média abaixo de cinco anos. Elevar a qualidade da educação básica permitirá ao País aumentar o estoque de capital humano com efeitos diretos nas estratégias da indústria, de melhorar a produtividade e a qualidade e de estimular a atividade de inovação nas empresas. (p. 31-32)

Em primeiro lugar, apresenta-se o cenário macrossocial em que se encontra a competição industrial, baseada nas inovações tecnológicas em escala mundial. A saída para que o país possa ser competitivo está na melhoria e na universalização da educação básica, caminho que vários países seguiram, com destaque para a Coreia do Sul. Sublinhe-se a ênfase na gestão de qualidade das escolas, bem como os projetos de qualidade total implementados ao longo da década de 1990 (FIDALG0; MACHADO; 1994; OLIVEIRA, 1996).

Em segundo lugar, para os empresários, um mundo em constante mutação como o de hoje demanda uma formação de trabalhadores voltada para a flexibilidade e para o enfrentamento de situações inesperadas e instáveis.

A qualidade da educação inicial e continuada deve necessariamente passar pela inclusão digital, tendo em vista a centralidade das tecnologias como propulsora das transformações produtivas e da competição em nível global. Nesse quesito, o Brasil ocupava a 39a posição no ranking mundial de países mais preparados para receber os benefícios das TI, posição que já foi melhor - o país era o $29^{\circ}$ colocado antes de 2003 (CNI, 2005).

Um último tema abordado no Mapa refere-se à educação empreendedora. Vejamos o que afirmam os empresários sobre isso:

A divulgação da cultura empreendedora e a valorização da atividade empresarial são essenciais para o crescimento do País. 0 elo de ligação é a interdependência entre empreendedorismo e inovação.

A sua difusão requer processos educativos capazes de formar profissionais para empreender e inovar.

Promover a cultura empreendedora na educação significa desenvolver valores para criar a prática de comportamentos individuais na busca de soluções e iniciativas na gestão do próprio negócio, na participação e organização das formas de geração de renda e emprego e na condição de cidadão ativo, como empreendedor social. (p. 34)

0 empreendedorismo constitui-se em uma das mais relevantes categorias da pedagogia dos empresários brasileiros. No excerto acima, os empresários afirmam o nexo entre empreendedorismo e inovação, o que requer a formação de um tipo de competência direcionada para a iniciativa individual dos educandos e voltada para a construção do próprio negócio ou para a atuação no interior das empresas, no sentido de auxiliarem no desenvolvimento de melhorias dos processos produtivos, na liderança e em iniciativas de forma geral.

\section{A Educação para a nova indústria}

Educação para a nova indústria (CNI, 2007) é o mais importante documento educacional da CNI nos anos 2000, e expressa sinteticamente seu projeto educacional. Ele é o guia das ações educacionais do Serviço Social da Indústria (SESI), que é a entidade do Sistema Indústria responsável pela educação básica em todo o país, e do Serviço Nacional de Aprendizagem Industrial (SENAI), responsável pela educação técnica e tecnológica do sistema. Esse documento é parte das ações do Mapa estratégico da indústria 2007-2015.

A missão do SESI é promover

a qualidade de vida do trabalhador, estimular a gestão socialmente responsável 
nas corporações industriais e contribuir para a competitividade e o desenvolvimento sustentável do país. (CNI, 2007, p. 45)

Sua estrutura é composta por 27 departamentos regionais e um departamento nacional; ele está presente em 2006 municípios brasileiros, empregando cerca de 50 mil profissionais. No ano de 2006, foram matriculados nas escolas do SESI de todo o país cerca de 1.768 .485 alunos (CNI, 2007).

Os programas desenvolvidos pelo SESI para a educação básica e continuada são os seguintes: Programa Sesi Educação do Trabalhador; Programa Sesi por um Brasil Alfabetizado; Programa Sesi de Educação Continuada; Atuação na Educação Infantil e Ensino Fundamental.

0 primeiro programa, que já atingiu cinco milhões de pessoas, objetiva elevar a escolaridade dos trabalhadores da indústria, oferecendo educação nos níveis fundamental e médio, com metodologias adaptadas às diferentes situações. 0 segundo é uma parceria com o governo federal para a erradicação do analfabetismo absoluto no país. 0 documento assinala o atendimento a mais de 900 mil pessoas. 0 programa de educação continuada constitui-se como uma mediação com a educação profissional, visando à formação de técnicos conforme as necessidades das indústrias em seus diferentes setores. Somente em 2006 foram realizadas 729.788 matrículas. A educação infantil e fundamental do sistema do SESI tem como meta a formação cidadã dos filhos dos trabalhadores da indústria. Em 2006 foram realizadas 211.868 matrículas em 6.576 turmas espalhadas pelo país (CNI, 2007).

0 princípio de que parte o documento é a relação estreita entre educação e desenvolvimento econômico, especialmente porque a produção industrial no mundo passa por transformações com a introdução de tecnologias, e o Brasil necessita colocar-se competitivamente na disputa por mercados, o que exige uma mão de obra qualificada. Nas palavras de Armando Monteiro Neto (CNI, 2007):
0 setor produtivo requer trabalhadores cada vez mais capacitados e qualificados. Disso decorre a necessidade de identificar quais as competências dos perfis profissionais desenhados para atender às novas demandas da indústria. 0 processo não é estanque, mas de grande sinergia: assim como a educação contribui para o avanço da indústria, esta, por sua vez, retribui provocando mudanças no ambiente educativo. (p. 8)

A educação, portanto, tem como finalidade contribuir para o desenvolvimento sustentável do país, meta desse programa da CNI. As mudanças que vêm ocorrendo seriam decorrentes de quatro fatores: novos perfis profissionais; novas regiões industriais; novas tecnologias; aceleração do ritmo de crescimento.

Quanto aos novos perfis profissionais, os industriais defendem que as mudanças tendem à incorporação de quadros com maior escolaridade, em especial de nível médio, superior e tecnólogos. Entretanto, reconhece o documento que a realidade brasileira não corresponde ao perfil desejado para o futuro da indústria competitiva, pois grande parte de sua mão de obra presente na indústria não possui sequer o ensino fundamental (cerca de 61\%, ou aproximadamente 2,4 milhões de trabalhadores).

As novas tecnologias de produção estão expostas no documento - automação industrial (Computer Aided Design / Computer Aided Manufacturing CAD/CAM; Controlador Lógico Programável - CLP); sistema de manufatura integrada (Computer Integrated Manufactoring - CIM; Sistema Digital de Controle Distribuído - SDCD) -, o que dá razão empírica aos argumentos sobre a centralidade da base microeletrônica da produção na acumulação flexível (HARVEY, 2002).

A esse respeito, mais uma vez os industriais explicitam a relação de subordinação da escola às demandas produtivas, o que é apresentado discursivamente como uma necessidade premente da sociedade. Trata-se de uma adequação da escola às novas tecnologias, como se pode observar no trecho a seguir: 
A demanda por recursos humanos mais qualificados nas empresas tem impacto sobre o conteúdo da formação dos novos profissionais e requer a modernização da infra-estrutura tecnológica das escolas e dos seus laboratórios. Exige-se educação continuada - ou aprendizagem ao longo da vida - em ambiente cada vez mais flexível, no formato e nos conteúdos.

A tendência internacional é, inicialmente, priorizar os cursos de formação generalista, para, em seguida e no âmbito da empresa, se fazer o aprofundamento da especialização, de acordo com as exigências dos novos padrões tecnológicos. (CNI, 2007, p. 16)

Ressalte-se a transparência da posição assumida. Os próprios industriais dão a receita para o sucesso do sistema educacional: uma educação generalista. Outra questão importante a ser depreendida desse excerto é que realmente a tendência à especialização nas empresas vem-se colocando como paradigma para a competitividade das organizações, as quais necessitam sempre atualizar seus quadros nas tecnologias que incorporam à produção a fim de que sua mão de obra não esteja aquém do desafio concorrencial de âmbito global.

Em resumo, afırma o documento que as bases para uma formação competente para as novas tecnologias devem levar em conta os seguintes itens: modernização das escolas; novos conteúdos de formação; educação a distância; aprendizagem flexível; educação empreendedora; educação na empresa.

Os padrões de gestão defendidos pela CNI estão articulados com o universo do chamado toyotismo (GOUNET, 1999; OLIVEIRA, 2004) - qualidade total; segurança no trabalho; economia de tempo e de materiais; gestão ambiental; pesquisa e desenvolvimento (P\&D) -, além de uma maior preocupação das empresas em oferecerem treinamento e capacitação, o que, de certa forma, explica a tendência à centralidade da educação básica como paradigma formativo.
Para responder aos desafios colocados ao capital nesse cenário contemporâneo de acirrada competitividade internacional, os empresários propõem o programa Educação para a nova indústria. Seus principais elementos são assim resumidos: expansão e diversificação da oferta de educação básica, continuada e profissional ajustada às necessidades atuais e futuras da indústria; modernização, otimização e adequação da infraestrutura física de escolas e laboratórios; flexibilização no formato e nas metodologias de atendimento às demandas educacionais da indústria; capacitação de docentes, técnicos e gestores em tecnologias e gestão dos processos educacionais (CNI, 2007).

0 programa da CNI tem grande ambição em termos de abrangência e resultados: com um orçamento de $\mathrm{R} \$ 10.450$ bilhões no período de 2007 a 2010, pretende atingir 16,2 milhões de matrículas no Sistema SESI e SENAI, sendo 7,1 milhões no SESI (educação básica e continuada) e 9,1 milhões no SENAI (educação profissional). No caso específico da educação básica de crianças e jovens, o montante é de 848 mil matrículas.

0 quarto capítulo do documento, denominado Propostas de ação, é o que trata mais especificamente da proposta empresarial para a educação básica por meio do SESI. 0 principal argumento em relação à educação em toda a extensão do documento é retirado da teoria do capital humano, tal como nos documentos anteriores. Isso fica evidente no trecho a seguir:

0 capital humano nas organizações, considerado na sociedade do conhecimento como o principal ativo das empresas, é formado pelo conjunto de habilidades que as pessoas detêm, adquiridas por meio de processos educativos, treinamento ou da experiência. As chamadas competências básicas, formadas pela educação básica e a continuada, são condição para o desenvolvimento das demais competências, inclusive as profissionais, na medida em 
que possibilitam continuar aprendendo e aperfeiçoando-se durante toda a vida. Tais aspectos têm adquirido crescente importância nas ações voltadas para o desenvolvimento socioeconômico e a melhoria da qualificação do perfil dos trabalhadores da indústria. A indústria competitiva depende de força de trabalho capacitada, o que implica melhorar os índices de escolaridade do trabalhador e garantir aos seus filhos educação de qualidade. 0 programa Educação para a Nova Indústria compreende todos esses temas. (p. 21)

Esse excerto é esclarecedor sobre vários aspectos. Em primeiro lugar, porque novamente evidencia a adesão da CNI à teoria do capital humano. Em segundo lugar, porque também expressa o papel que a educação básica cumpre no tocante à formação de trabalhadores produtivos para o país, ou seja, a formação das chamadas competências básicas, que possibilitam a continuidade do aprendizado dos trabalhadores e abrem caminho para o desenvolvimento de novas competências demandadas pela indústria.

Para colocar em marcha os propósitos relacionados à educação básica e continuada, o programa propõe dois objetivos:

0 primeiro consiste na melhoria das condições técnico-pedagógicas, que compreende a ampliação do tempo de permanência de crianças e jovens na escola, a aquisição de recursos paradidáticos e a formação do educador. 0 segundo está voltado para a expansão da oferta de educação básica e continuada, com prioridade para o trabalhador da indústria. Estão também previstas ações com vistas à melhoria da educação básica do País. (p. 22)

0 primeiro objetivo preocupa-se com as mudanças no campo técnico-pedagógico para adequar a educação oferecida no Sistema CNI aos novos paradigmas educacionais. Quanto à expansão da educação básica e continuada, a meta para o período entre 2007 e 2010 é realizar 7.154.000 matrículas, distribuídas da seguinte forma: 848.000 na educação básica de crianças e jovens; 2.306 .000 na modalidade de educação básica de jovens e adultos; e 4.000.000 na modalidade de educação continuada (CNI, 2007).

Outra linha de ação proposta pelos industriais é a chamada escola de tempo integral, a qual, segundo o documento:

Visa melhorar a qualidade da educação, ampliando o tempo de permanência nas escolas do SESI de crianças e jovens da educação básica, articulando as ações de ensino-aprendizagem com ações de cultura, esporte e lazer e, no que concerne ao nível médio, com a educação profissional.

A escola de tempo integral atualiza o conceito de currículo, possibilitando ao aluno adquirir hábitos de vida saudável, ampliar o capital cultural, incentivar a leitura, conhecer novos idiomas, participar de processos de inclusão digital e de formação profissional. (p. 22)

A partir dessa proposta para a educação integral no Sistema CNI, compreende-se que os industriais encaram a formação educativa no nível básico com foco na ampliação do capital cultural geral, ou seja, em cultura, esporte e lazer, que são os fundamentos da ação do SESI desde sua fundação. No nível médio, o SESI tem como projeto a relação da educação básica e a formação profissional, a fim de preparar, ainda que básica e genericamente, os futuros trabalhadores da indústria.

Na segunda parte do excerto, constatase claramente a linha do projeto do SESI de educação do corpo e da mente por meio de lazer, esporte, cultura, hábitos de vida saudável etc. Esse é o cenário em que se materializa o projeto de educação generalista já afirmado como objetivo educacional no Sistema CNI, uma educação voltada à aquisição de capital cultural. 
A meta até 2010 é que 40\% das matrículas da educação básica sejam em período integral. Para o ensino médio, a meta é ampliar as matrículas, nesse mesmo período, em 93\%, atingindo um total de 17.000 alunos, sendo que 75\% das vagas serão oferecidas em articulação com a educação profissional.

Conforme foi destacado anteriormente, os industriais acreditam na educação básica como sendo o alicerce para a continuidade dos estudos e do aprimoramento de conhecimentos. Dessa forma, o forte investimento em educação básica tem razão de ser pela necessidade de flexibilização da mão de obra na indústria com a implementação da base microeletrônica.

As metas para a elevação da escolaridade são as seguintes:

- Promover a conclusão do ensino fundamental de $40 \%$ da força de trabalho da indústria, que hoje é analfabeta ou tem menos de oito anos de escolaridade $(1,02$ milhões de trabalhadores).

- Promover a conclusão do ensino médio de 30\% da demanda por esse nível de formação (690 mil trabalhadores). Para 50\% dos trabalhadores da indústria atendidos pelo programa (850 mil alunos), serão oferecidos currículos articuladores, voltados para o desenvolvimento de competências básicas e específicas do mundo do trabalho.

- Conclusão da educação básica de 600 mil jovens e adultos dependentes do trabalhador e comunidade. (p. 23)

0 documento assinala que o cumprimento de tais metas necessita de parcerias com o setor produtivo a fim de desenvolver currículos contextualizados com as necessidades desse setor, estas relacionadas com a educação básica e profissional.

\section{A indústria e o Brasil: uma agenda para crescer mais e melhor}

Esse documento é o mais recente da CNI (2010a) voltado ao diálogo com os candidatos à Presidência da República, tradição iniciada nas eleições de 1998. Ele também se encontra ajustado ao Mapa estratégico da indústria (CNI, 2005), que tem seu cronograma previsto até o ano de 2015. Sem grandes novidades em relação ao documento anteriormente analisado, Educação para a nova indústria, já que este é a grande síntese dos empresários no campo, o que mais interessa verificar aqui é a relação entre educação, inovação, produtividade da indústria e competitividade em nível global.

A educação é apontada pelos empresários como elemento fundamental para a produtividade e a inovação, pois eles claramente adotam a perspectiva de que o desenvolvimento dos recursos humanos das empresas resulta em uma melhor adaptação do trabalhador às mudanças produtivas impostas pelas novas bases técnicas de produção microeletrônica. Como já foi anunciado anteriormente, há, na proposição empresarial, uma retomada da teoria do capital humano, agora muito fortemente focada na qualidade da educação básica, a qual possibilita o aprender a aprender ao longo da vida ${ }^{6}$.

Para além da educação básica, afırmam os empresários, o Brasil necessita da formação de quadros técnicos de nível superior, especialmente de engenheiros e cientistas capazes de provocar inovações nos processos produtivos (CNI, 2010a). Nesse sentido a universidade precisaria ser repensada para uma mudança estrutural capaz de superar o academicismo, focando a atuação nas demandas do setor produtivo.

A lógica capitalista e o investimento em educação na atual fase de alta competitividade estão, segundo a CNI, no desenvolvimento dos recursos humanos, pois este é o elemento que possibilita a ampliação da produtividade e a valorização do capital, já que outros fatores, como os recursos naturais, têm limites claros para sua expansão. Portanto, na ótica empresarial, a nação que mais investe em uma educação com a qualidade voltada para a formação de mão de obra capaz de produzir mais, melhor,

6 - Não entraremos aqui nesta discussão, fartamente levada a cabo por Duarte (2000). 
com menos custo e em menos tempo estará na frente nessa acirrada disputa. E é a indústria o motor desse desenvolvimento, pois ela é o setor que mais pode incluir novas tecnologias e generalizar seu uso, atingindo inclusive outros setores da economia. É também a indústria que mais se insere no mercado concorrencial internacional, tendo, portanto, de adaptar-se aos padrões globais da concorrência capitalista, necessitando de inovações constantes geradoras de vantagens competitivas ao capital.

Os empresários contam com uma vantagem adicional do país para as próximas décadas, que é a janela de oportunidade demográfica, ou seja, o cenário que teremos até aproximadamente 2055, em que haverá no país uma relação mais proveitosa entre a população em idade ativa (PIA) e as pessoas dependentes das contribuições sociais, como crianças, jovens e idosos aposentados.

Para que esse potencial seja plenamente aproveitado é imprescindivel intensificar os investimentos em educação e em qualificação profissional. A dinâmica populacional passa a exigir melhoria substantiva da política educacional e, proporcionalmente, menor aumento quantitativo.

Se as políticas educacionais e de qualificação nos próximos anos forem efetivas, o Brasil contará, nas próximas décadas, com um nível de acumulação de capital humano ímpar na história do País uma força de trabalho mais experiente, mais qualificada e com melhores índices de produtividade. (CNI, 2010a, p. 68)

A proposição dos empresários é bem clara no sentido de que não se pode perder essa oportunidade histórica de formar em massa uma mão de obra qualificada para a nova indústria (CNI, 2007), evidenciando a relação entre educação e produtividade.

Uma das propostas da CNI para a melhoria da produtividade pela qualificação dos trabalhadores é desenvolver, na indús- tria, uma cultura de efetivo envolvimento dos trabalhadores nas decisões das empresas, visando à melhoria dos processos produtivos; para isso, o trabalhador precisa ter uma boa formação básica e técnica e estar disponível à formação continuada.

Uma questão bastante debatida pelos empresários em todos os documentos em que tornam públicas suas opiniões é a legislação trabalhista brasileira. Reclamam os empresários do engessamento da legislação trabalhista sobre a produtividade, pois ela não abre brechas para contratações flexíveis, mais de acordo com o perfil dos trabalhadores vinculados à parte mais dinâmica da produção, que trabalham com ferramentas de tecnologia da informação e com uma dinâmica dificilmente prevista na Consolidação das Leis do Trabalho (CLT). Soma-se a isso algo mais generalizado, ou seja, "a rigidez das leis atuais, a complexidade burocrática e as altas despesas de contratação" (CNI, 2010a, p. 109), e todo o ambiente necessário para a produtividade, a eficiência e a eficácia da indústria ficam comprometidos. Pleiteiam os empresários uma maior flexibilidade nessas relações entre capital e trabalho, as quais se deveriam basear na produtividade e no mérito como meios de manter os empregos, quebrando a lógica denominada por eles de "globalização de direitos” (p. 113) que rege a legislação trabalhista e as ações sindicais.

A terceirização livre das atividades produtivas tem sido apontada pela CNI como meio eficiente de aumentar a produtividade, mas isso não ocorre atualmente, pois a legislação impede a terceirização das chamadas atividades-fim das empresas, algo contestado pelos empresários como antiquado e um freio à produtividade. Sobre tais questões trabalhistas, os empresários ainda enumeram os salários, os benefícios, as obrigações acessórias e os passivos como mecanismos refreadores da atividade econômica e da produtividade, devido ao alto custo que geram para as empresas, desestimulando-as ao investimento em recursos humanos. 
Com relação à inovação, o documento a trata como "o grande motor da produtividade" (p. 165), e dedica um capítulo específico ao tema, considerado como o "centro da agenda de política industrial dos países mais desenvolvidos" (p. 165) e, portanto, também do Brasil. Aqui, devido aos ônus históricos, à grande carga tributária, aos problemas de infraestrutura e a outros custos dos fatores de produção, a inovação aparece como ainda mais relevante para a agenda industrial brasileira.

Segundo a CNI, inovação

envolve novos produtos e processos, formas novas de comercializar, de transformar o relacionamento com clientes e fornecedores, de organizar a produção e de novos serviços que agregam valor. (p. 165)

Sem dúvida, a lógica da produção capitalista - conforme constataram Marx e Engels desde o Manifesto comunista (MARX; ENGELS, 1999), mais especificamente Marx, no capítulo $\mathrm{X}$ do Livro I de $O$ capital, ao analisar o processo de extração da mais-valia relativa (MARX, 1998) - exige, por parte dos capitalistas, uma incessante luta contra a inércia produtiva, levando-os a buscarem inovações constantes para que possam competir nos mercados e sobreviverem como capitalistas. A inovação tem um papel fundamental para isso, pois é dela que advêm as vantagens competitivas das indústrias, colocando-as no topo da competição no período em que as inovações não são generalizadas pela concorrência.

Como no que concerne a outros fatores produtivos, o Brasil encontra-se muito defasado em relação à taxa de inovação, conforme constatou a CNI e outros estudos; e a maioria das empresas que inovam são de grande porte, com mais de 500 funcionários, chegando a 79,2\% entre os anos de 2003 e 2005 (CNI, 2010a). A comparação com os países da Organização para Cooperação e Desenvolvimento Econômico (OCDE) deixa o Brasil em uma posição problemática. Além disso, o tipo de inovação levada a efeito pelas empresas brasileiras geralmente é a introdução de novas máquinas no processo produtivo, e a CNI indica a necessidade de ampliar a gama de possibilidades inovadoras.

Existe, no cenário macroeconômico brasileiro, um entrave à inovação, pois sendo esta uma atividade de risco, ela necessita, segundo os empresários, do apoio governamental e de parceiros privados. 0 Estado deveria ser o grande comprador dos produtos inovadores como são, por exemplo, os Estados Unidos e também garantir subsídios contra os riscos. Segundo o documento:

É preciso ampliar significativamente a estrutura de apoio às empresas que querem inovar, por meio de parceiros públicos e privados capazes de prestar serviços, ofertar consultoria, melhorar a gestão da inovação das empresas, assessorar na definição de estratégias e planos de inovação, implantar e medir os resultados desses planos. (p. 171)

0 incentivo à inovação por parte do Estado, quando ocorre, dá-se apenas às grandes empresas, cujos lucros são reais, e deixa de lado as pequenas e médias empresas, as quais, por sua vez, teriam um grande potencial inovador que acaba não se concretizando por falta de apoio, o que se torna um gargalo da política industrial. Além disso, o apoio estatal à inovação no Brasil sofre de uma grave distorção, que é a centralidade da Lei de Informática como principal incentivadora da inovação, o que reduz o campo de possibilidades inovadoras, restringindo-o a apenas parte do fator Pesquisa e Desenvolvimento (P\&D) das empresas. 0 resultado disso é que apenas $6,4 \%$ das empresas utilizavam-se de algum tipo de apoio em seus projetos de inovação. Das empresas que inovaram, apenas 19,1\% receberam apoio governamental, o que ocorreu, na maioria dos casos, apenas para compras de equipamentos. 
Com relação à institucionalidade da inovação no quadro do Estado brasileiro, a CNI reclama da ausência de diálogo entre os órgãos que apoiam a inovação, loteados no Ministério da Ciência e Tecnologia, e as áreas econômicas do governo, o que não é o modelo ideal pensado pela entidade. Para que o quadro fosse revertido institucionalmente, seria preciso que a inovação estivesse presente em um órgão diretamente ligado à Presidência da República, ou que se promovesse o diálogo entre as áreas da ciência, da tecnologia e da economia.

Porém, como afirmam os empresários, nada disso tem sentido se não houver uma verdadeira revolução educacional, no sentido de que a escola passe a adequar-se às necessidades da produção. A qualificação do trabalho no país é essencial para que os trabalhadores possam tomar ciência das inovações, trabalhar com elas e também aperfeiçoá-las, ou seja, não apenas importá-las. No item seguinte será analisado um documento ainda mais recente da CNI (2010b), objetivando compreender a relação existente entre a educação e a competitividade da indústria na visão da entidade.

\section{Competitividade Brasil 2010: uma} comparação com países selecionados

Esse é um documento que expressa de forma mais acentuada a agenda da competitividade da indústria, ainda mais relevante devido "ao avanço do processo de globalização e remoção progressiva das barreiras ao comércio entre países" (CNI, 2010b, p. 11). Logo de partida, portanto, os empresários delineiam a cabal necessidade de aperfeiçoar os processos produtivos com vistas à competição e, logo, à sobrevivência no mercado cada vez mais acirrado. Uma forma de fazer isso é ter parâmetros de comparação entre empresas ou países, de forma que uma pesquisa como a ensejada - que reverteu na produção do documento - serve de parâmetro para tomadas de decisões empresariais e governamentais. A CNI define competitividade nos seguintes termos: "capacidade da empresa de igualar ou superar seus concorrentes na preferência dos consumidores" (p. 11); tal preferência pode ser conquistada pela determinação do preço das mercadorias ou pela diferenciação deste em relação aos dos produtos existentes no mercado, o que envolve qualidade, inovação e propaganda.

A comparação entre países é imprescindível, pois é de nível mundial a concorrência entre as indústrias; o documento, porém, parte de comparações entre o Brasil e países relativamente equivalentes no nível de desenvolvimento industrial, com os quais compete diretamente e cujos dados não são tão díspares. Os países escolhidos foram: África do Sul, Argentina, Austrália, Canadá, Chile, China, Colômbia, Coreia, Espanha, Índia, México, Polônia e Rússia.

Os fatores analisados para avaliar a competitividade são quatro: disponibilidade e custo da mão de obra; disponibilidade e custo de capital; infraestrutura e logística; peso dos tributos. Parece evidente, pelo exposto até aqui, que o fator mão de obra, sua disponibilidade e seu custo referem-se mais proximamente à questão educacional.

Antes de adentrar essa análise, porém, vale destacar que o Brasil está em uma posição desfavorável em relação aos outros 13 países. No fator disponibilidade e custo de mão de obra, os piores índices referem-se ao custo da mão de obra (11ํ lugar de 11 países), produtividade do trabalho industrial $\left(11^{\circ}\right.$ entre 13 países $^{7}$ ) e rigidez no emprego (130 lugar), fatores estes já aqui destacados nos documentos anteriores, e que são alvos de críticas constantes dos empresários. Apenas no que se refere à população economicamente ativa o Brasil destaca-se como $2^{\circ}$ lugar, devido à oportunidade aberta pela pirâmide demográfica já tratada aqui. Em outros três fatores que completam os dados analisados acerca da mão de obra, o país encontra-se em posição intermediária: níveis

7 - 0 documento esclarece que, em relação à China e à Índia, a baixa remuneração compensa a baixa produtividade de mão de obra. 
de remuneração na indústria manufatureira $\left(5^{\circ}\right.$ lugar entre 11 países), disponibilidade de mão de obra ( $8^{\circ}$ lugar) e crescimento da força de trabalho (8º lugar).

Tais dados repetem-se com relação aos outros três fatores demonstrados no documento $^{8}$, o que, evidentemente, é um sinal de alerta para a burguesia nacional em sua empreitada constante pela competição. Tais problemas devem-se, em grande parte, ao clima macrossocial, e o Estado brasileiro tem um papel importante em melhorar os fatores de competição; daí a insistência dos empresários - particularmente, da CNI - para que os governos possam levar adiante, como projeto de Estado, e não apenas de governos, sua agenda de competitividade, que envolve a qualidade da educação, o incentivo à inovação e à produtividade e a eliminação de várias barreiras ao comércio, como a burocracia, os impostos, a infraestrutura e a rigidez das relações trabalhistas.

A análise do fator educacional considera três elementos: disseminação da educação, qualidade do ensino e recursos destinados à educação. Para os dados educacionais, somente nove países foram comparados, por falta de dados disponíveis, são eles: Austrália, Canadá, Chile, Coréia do Sul, Espanha, México, Polônia e Rússia. Dentre eles, o Brasil ocupa a última posição no cômputo geral. Segundo constatação da CNI (2010b):

0 contraste das posições relativas aos gastos públicos com educação com aquelas mais desfavoráveis referentes à disseminação da educação e à qualidade do ensino põe em questão a eficiência e eficácia do gasto público em educação no País. (p. 57)

0 único fator positivo é a matrícula no ensino médio, que coloca o Brasil entre

8 - No fator disponibilidade e custo de capital, o Brasil ocupa a última posição, devido ao alto custo do capital. No fator infraestrutura e logística, ocupamos a $12^{\mathrm{a}}$ posição, devido à infraestrutura de transportes. No tocante ao peso dos tributos, 0 Brasil está em $13^{\circ}$ lugar. os primeiros países; mas, no que concerne à conclusão tanto do ensino médio, quanto do ensino superior, a posição brasileira é desfavorável.

Com relação à qualidade, o país está na $10^{a}$ posição entre 12 países, à frente apenas da Argentina e da Colômbia. A CNI leva em consideração testes internacionais como o Programa Internacional de Avaliação de Alunos (PISA), no qual o país ficou em último lugar em matemática, em $10^{\circ}$ lugar em leitura e em $11^{\circ}$ em ciências. É importante lembrar que esses três campos são fundamentais para a produtividade dos trabalhadores, levando-se em conta as novas demandas produtivas.

0 documento constata que, apesar das posições desfavoráveis do Brasil na educação, o mesmo não ocorre com relação ao investimento em educação, relacionando Produto Interno Bruto (PIB) e população. Nesse caso, o país ocupa o $6^{\circ}$ lugar. No que se refere ao gasto público per capita, o país ocupa a 9a posição.

\section{Considerações finais à guisa de crítica ao projeto educacional da CNI}

Este trabalho partiu da análise de quatro documentos de naturezas diferentes produzidos pela CNI para um diálogo com a sociedade sobre seu projeto de país, incluindo-se aí as propostas de educação básica articuladas às novas demandas da produção de cunho técnico microeletrônico.

0 ciclo em que se encontra o projeto pode ser sintetizado da seguinte forma: com uma educação básica de qualidade, os trabalhadores podem assimilar inovações externas, adaptando-se a elas, e, ao mesmo tempo, promover inovações; para tanto, segundo os empresários, deve-se investir na participação dos trabalhadores nas decisões empresariais. Além disso, com uma boa formação adaptada aos novos padrões, os trabalhadores tornam-se mais produtivos e, com isso, a indústria brasileira torna-se mais 
competitiva internacionalmente. Eis o círculo virtuoso apresentado pelos empresários, o qual culmina na manutenção e na criação de empregos e de renda, incentivando o consumo e, logo, a produção. Tudo isso deve contar com um ambiente macrossocial favorável à indústria, o que, segundo os empresários, deve ser papel do Estado brasileiro.

A partir dos estudos aqui indicados, outros podem ser desenvolvidos, sempre focados na relação entre os projetos da burguesia industrial brasileira e as políticas educacionais dos governos. Outras temáticas de grande relevância emergem atualmente, como o estudo da inovação, da tecnologia, da produtividade e da competitividade, bem como o papel da escola na formação de trabalhadores às atuais circunstâncias históricas referentes à produção.
Fica evidente, na proposição dos empresários, a existência de um projeto nacional voltado para a manutenção da ordem social e para o fim das lutas entre capital e trabalho. Para os trabalhadores, resta situar-se perante tal projeto, seja para a ele se adaptar, como está presente no senso comum, ou para, a partir da compreensão de seus fundamentos, posicionar-se criticamente a ele, podendo, com isso, construir outro projeto de sociedade.

Com este artigo, esperamos poder contribuir para outras leituras de tais documentos, os quais, sabemos, apresentam diferentes possibilidades interpretativas que aqui apenas puderam ser esboçadas. De qualquer forma, porém, os documentos da CNI são importantes mediadores para o conhecimento do projeto da burguesia industrial brasileira. 


\section{Referências}

BOITO JUNIOR, Armando. A hegemonia neoliberal no governo Lula. Crítica Marxista, Rio de Janeiro, n. 17, p. 10-36, 2003.

A burguesia no governo Lula. Crítica Marxista, Rio de Janeiro, n. 21, p. 52-77, 2005.

. Estado e burguesia no capitalismo neoliberal. Revista de Sociologia e Política, Curitiba, n. 28, p. 57-73, jun. 2007.

BOURDIEU, Pierre. A escola conservadora: as desigualdades frente à escola e à cultura. In: NOGUEIRA, Maria Alice; CATANI, Afrânio (Orgs.). Escritos de educação. 9. ed. Petrópolis: Vozes, 2007a. p.41-64.

. Os três estados do capital cultural. In: NOGUEIRA, Maria Alice; CATANI, Afrânio. (Orgs.). Escritos de educação. 9. ed. Petrópolis: Vozes, 2007b. p.73-79.

CNI (Confederação Nacional na Indústria). Mapa estratégico da indústria: 2007-2015. Brasília, DF: CNI, 2005.

. Educação para a nova indústria: uma ação para o desenvolvimento sustentável do Brasil. Brasília, DF: CNI, 2007.

. A indústria e o Brasil: uma agenda para crescer mais e melhor. Brasília, DF: CNI, 2010a.

Competitividade Brasil 2010: comparação com países selecionados. Uma chamada para a ação. Brasília, DF: CNI, 2010b.

COSTA, Márcio da. Famílias e acesso diferenciado a escolas públicas prestigiadas: um estudo de caso. Educar em Revista, Belo Horizonte, v. 26, n. 02, p. 227-248, ago. 2010. Disponivel em: <http://www.scielo.br/pdf/edur/v26n2/a11v26n2.pdf>. Acesso em: 26 jan. 2011.

DUARTE, Newton. Vigotski e 0 aprender a aprender: crítica às apropriações neoliberais e pós-modernas da teoria vigotskiana. Campinas: Autores Associados, 2000.

FERRETTI, Celso. et al. Empresários, trabalhadores e educadores: diferentes olhares sobre as relações de trabalho e educação no Brasil nos anos recentes. In: LOMBARDI, José Claudinei; SAVIANI, Demerval; SANFELICE, José Luís (Orgs.). Capitalismo, trabalho e educação. Campinas: Autores Associados; HISTEDBR, 2002. p. 97-118.

. Escola e fábrica: vozes de trabalhadores em uma indústria de ponta. Cadernos de Pesquisa, São Paulo, n. 118, mar. 2003.

FIDALGO, Fernando Selmar; MACHADO, Lucília (Orgs.). Controle da qualidade total: uma nova pedagogia do capital. Belo Horizonte: Movimento de Cultura Marxista, 1994.

FRIGOTTO, Gaudêncio. A produtividade da escola improdutiva. São Paulo: Cortez; Autores Associados, 1984.

A relação da educação profissional e tecnológica com a universalização da educação básica. Educação e Sociedade, Campinas, v. 28, n. 100 - Especial, p. 1129-1152, out. 2007. Disponível em: <http://www.scielo.br/pdf/es/ v28n100/a2328100.pdf>. Acesso em: 03 set. 2008.

GOUNET, Thomas. Fordismo e toyotismo na civilização do automóvel. São Paulo: Boitempo, 1999.

HARVEY, David. A condição pós-moderna. 11. ed. São Paulo: Loyola, 2002.

INVERNIZZI, Noela. Novos rumos do trabalho: mudanças nas formas de controle e qualificação da força de trabalho brasileira. 470p. Tese (Doutorado em Política Científica e Tecnológica) - Instituto de Geociências, Universidade Estadual de Campinas, 2000.

KUENZER, Acácia Zeneida. 0 ensino médio agora é para a vida. Educação e Sociedade, v. 21, n. 70, abr. 2000.

. As relações entre conhecimento tácito e conhecimento científico a partir da base microeletrônica: primeiras aproximações.

Educar em Revista, Curitiba, v. 21, n. 2, Especial, p. 43-69, 2003. 
Competência como práxis: os dilemas da relação entre teoria e prática na educação dos trabalhadores. Boletim técnico do SENAC, Rio de Janeiro, v. 30, p. 81-93, 2004.

. Da dualidade assumida à dualidade negada: 0 discurso da flexibilização justifica a inclusão excludente. Educação e Sociedade, Campinas, v. 28, n. 100, out. 2007.

MARX, Karl. 0 capital, Livro I. Rio de Janeiro: Civilização Brasileira, 1998.

MARX, Karl; ENGELS, Friedrich. Manifesto comunista. 5. ed. Rio de Janeiro: Paz e Terra, 1999.

MELO, Alessandro de. Educação básica e formação profissional na visão dos empresários brasileiros. Educação e Sociedade, Campinas, v. 30, n. 108, p. 893-914, out. 2009.

0 projeto pedagógico da Confederação Nacional da Indústria para a educação básica nos anos 2000. 258p. Tese (Doutorado em Educação) - Universidade Federal do Paraná, Curitiba, 2010a.

A reforma trabalhista como limite do projeto de educação básica do empresariado brasileiro. In: SEMINÁRIO DO TRABALHO, 7., 2010, Marília. Anais..., Marília, 2010b.

NOGUEIRA, Maria Alice. Elites econômicas e escolarização: um estudo de trajetórias e estratégias escolares junto a um grupo de famílias de empresários de Minas Gerais. Tese apresentada para concurso de professor titular FAE/UFMG, 2002.

NOGUEIRA, Maria Alice; AGUIAR, Andréa. A escolha do estabelecimento de ensino e o recurso ao internacional. Atos de Pesquisa em Educação, v. 2, n. 1, p. 3-22, jan./abr. 2007. Disponível em: <http://proxy.furb.br/ojs/index.php/atosdepesquisa/article/ view/164/126>. Acesso em: 10 mar. 2010.

OLIVEIRA, Dalila Andrade. A qualidade total na educação: os critérios da economia privada na gestão da escola pública. In: BRUNO, Lúcia (Org.). Educação e trabalho no capitalismo contemporâneo: leituras selecionadas. São Paulo: Atlas, 1996. p. 57-90.

OLIVEIRA, Eurenice de. Toyotismo no Brasil: desencantamento da fábrica, envolvimento e resistência. São Paulo: Expressão Popular, 2004.

SALM, Cláudio; FOGAÇA, Azuete. Estudo da competitividade da indústria brasileira: condicionantes sociais da competitividade: educação básica e competitividade. Campinas: UNICAMP/UFRJ, 1993.

SCHULTZ, Theodore. 0 capital humano. Rio de Janeiro: Zahar, 1973.

SIMONSEN, Mário Henrique. 0 esforço educacional. In: SIMONSEN, Mário Henrique; CAMPOS, Roberto 0. A nova economia brasileira. Rio de Janeiro: Biblioteca do Exército Editora; Livraria José Olympio Editora, 1975. p. 151-174.

Recebido em: 07.10.2010

Aprovado em: 09.05.2011

Alessandro de Melo é professor adjunto do Departamento de Pedagogia da Universidade Estadual do Centro-0este, doutor em Educação pela Universidade Federal do Paraná (UFPR) e mestre em Educação Escolar pela Universidade Estadual Paulista "Júlio de Mesquita Filho" (UNESP). 
